\title{
Practices in child growth monitoring in the countries of the Eastern Mediterranean Region
}

\author{
A. Abul-Fadl, ${ }^{1}$ K. Bagchi' ${ }^{2}$ and L. Cheikh Ismail ${ }^{2}$
}

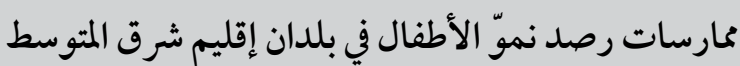

$$
\begin{aligned}
& \text { عزة أبو الفضل، كونال باجشي، ليلى الشيخ إسماعيل }
\end{aligned}
$$

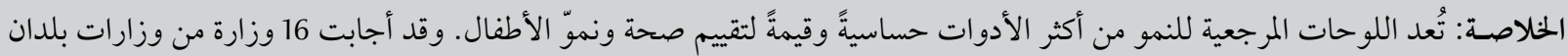

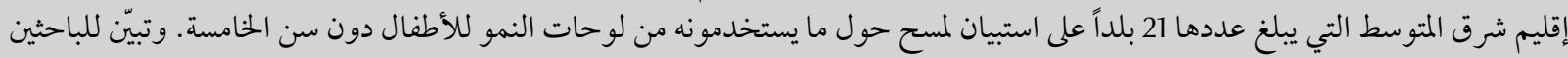

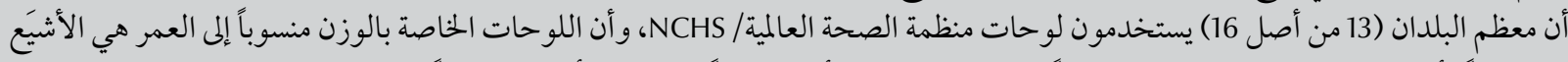

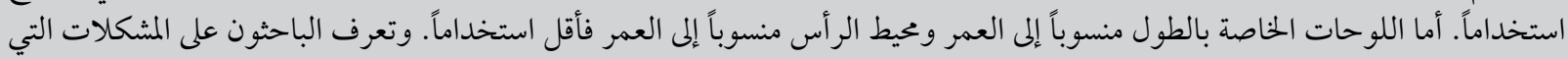

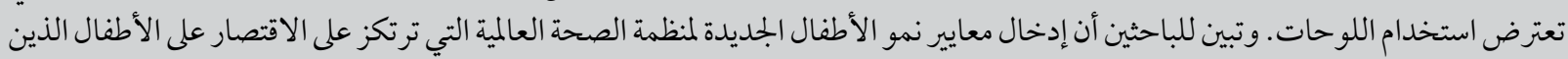

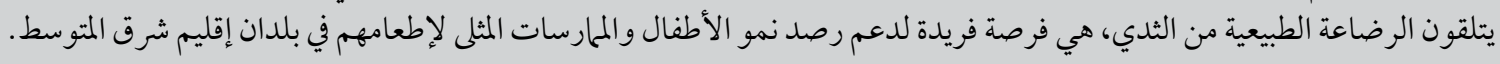

ABSTRACT Growth reference charts are among the most sensitive and valuable tools for assessing the health and development of children. A questionnaire survey was answered by 16 of the 21 ministries of health in the Eastern Mediterranean Region countries (EMR) about their use of growth charts for children under 5 years. Most of the countries (13/16) used the NCHS/WHO charts and weight-for-age was the most commonly used. Charts for height-for-age and head circumference-for-age were less commonly used. Problems in the use of charts were identified. The introduction of the new WHO Child Growth Standards, based on exclusively breastfed babies, is a unique opportunity to support growth monitoring and optimal feeding practices in EMR.

Pratiques en termes de suivi de la croissance des enfants dans les pays de la Région de la Méditerranée orientale

RÉSUMÉ Les courbes de croissances de référence figurent parmi les outils les plus sensibles et les plus fiables pour évaluer la santé et le développement de l'enfant. Seize (16) des 21 ministères de la Santé de la Région de la Méditerranée orientale ont répondu à une étude par questionnaire concernant l'utilisation des courbes de croissance chez l'enfant de moins de cinq ans. La plupart des pays (13/16) ont recours aux courbes NCHS/OMS et le rapport poids/âge était le plus fréquemment utilisé. Les courbes pour les rapports taille/âge et circonférence du crâne/âge étaient moins couramment usitées. Quelques problèmes relatifs à l'utilisation des courbes ont été identifiés. L'introduction des nouvelles normes OMS de croissance de l'enfant, basées uniquement sur les bébés allaités exclusivement au lait maternel, est une occasion unique pour encourager le suivi de la croissance et des pratiques optimales en matière de nutrition dans les pays de la Région de la Méditerranée orientale

'Department of Paediatrics, University of Benha, Faculty ofMedicine, Benha, Egypt (Correspondence to A.Abul-Fadl: azfadl@yahoo.com). ${ }^{2}$ Regional Office for the Eastern Mediterranean, World Health Organization, Cairo, Egypt.

Received: 02/09/07; accepted: 13/11/07 


\section{Introduction}

The first 5 years of life are crucial for ensuring adequate nutrition, growth and development of the child. Child growth monitoring allows mothers and parents to be well-informed and empowered with a simple tool for monitoring the growth and development of their children. It also allows health workers, through a cost-effective tool, to assess and monitor the growth and nutritional status of children for supporting exclusive breastfeeding in the first 6 months, timely adequate complementary feeding practices and continued breastfeeding for 2 years or more [ $1-3]$.

For the past 3 decades the growth reference charts of the National Center for Health Statistics/World Health Organization (NCHS/WHO) have been the internationally recommended charts for use by nutritional surveillance programmes [4]. Their cut-offs have been the standard reference for most of the national demographic surveys for assessing nutritional status of children and evaluating the effect of nutritional interventions as well as prioritizing country needs and identifying communities at risk of malnutrition [5]. However, their use as a reference for growth monitoring has been shown to be unsuitable for breastfed babies [6-9]. Recently WHO has developed new growth charts that reflect the growth of exclusively breastfed infants and are representative of an international sample of children from different regions of the world $[10,11]$. Evaluation studies conducted for the application of the new WHO Child Growth Standards (WHO-CGS) in clinical practice has shown them to be clinically sound [12]. Children monitored by the WHO-CGS were judged to be less stunted and less overweight than those assessed using the Centers for Disease Control 2000 (CDC2000) growth charts. Hence the WHO-CGS will assist in reducing the unnecessary referral of underweight and stunted children, while they should improve the detection of overweight and obese children [13].

Based on the above, the nutrition team in the WHO Regional Office for the Eastern Mediterranean (EMRO) carried out a survey to assess the current use of growth charts in the countries of EMR and to understand what additional measures need to be taken into account for effective utilization of the new WHO-CGS.

\section{Methods}

The study was carried out in countries of the EMR by the nutrition section of EMRO in 2005-06. Data were collected through a questionnaire survey developed by EMRO. The questions were revised, pretested and finalized by the EMRO team in the nutrition department. The 17-question format was short to ensure clarity and validity of collected information. Only one language (English) was used to ensure reliability. The questions assessed which growth charts were in use and how they were used for growth monitoring as well the problems facing health staff in the use of the growth charts for growth monitoring.

The questionnaires were distributed through the WHO Representative Offices in each country to the counterparts in the ministry of health $(\mathrm{MOH})$ of each country with a covering letter about the purpose of the survey and how to compile the data together with reference material about the development of the new international WHO-CGS. Representative Offices were urged to attach all the relevant information and documents used for growth monitoring by their country's $\mathrm{MOH}$ and its partner health organizations. Non-respondents were followed up by personal contact by phone and electronic mail. A consultant specialized in growth monitoring in children was recruited to administer the questionnaire survey in the country, conduct selected country visits to ascertain facts and accuracy of the information on growth monitoring available at EMRO, conduct direct interviews with growth monitoring specialists in selected countries and obtain additional information as required.

The questionnaires were compiled by the officials who were responsible for the growth monitoring programme in the $\mathrm{MOH}$ of each country, supported by relevant documents, including the growth charts used and the training materials and training activities being carried out. Other responses came from the officials of counterparts working with the $\mathrm{MOH}$ services such as universities or teaching institutions or private nongovernmental organizations that have widespread country health delivery services, as in the case of Lebanon. All data were supported by verification documents.

In-depth country case studies were conducted in Yemen, Egypt and the Libyan Arab Jamahiriya using the same formats. The investigator visited several governorates (regions) in each country: in Yemen, Sana'a city in the north, Ibb in the south-east and Taiz in the south; in the Libyan Arab Jamahiriya, Tripoli in the north, Benghazi in the north-east and Gharyan and Sebha in the south; in Egypt, Cairo, Alexandria and Damietta in the north and Assiut in the south. In each area officials in the health directorate, hospitals and health centres were interviewed using the $\mathrm{WHO}$ questionnaire format as a basis for in-depth interviews.

The survey extended from the spring of 2005 to September 2005. The country in-depth study was conducted over a period of 12 weeks.

\section{Statistical analysis}

The data were compiled by computer and analysed using a Microsoft Excel 2000 database. The in-depth and person-to-person interviews in each 
of the 3 countries were compiled by qualitative methods (transcription, coding, sorting and interpretation). The data were presented as frequency distributions for descriptive purposes using tables and charts.

\section{Results}

Out of the 21 countries targeted in the Region, 16 responded. In each country more than 1 official from the maternal and child health or nutrition departments in the $\mathrm{MOH}$ responded (Table 1). The 5 countries that did not respond were: Djibouti, Iraq, Somalia, Afghanistan and Tunisia.

The types of growth reference charts in use for child growth monitoring varied from one country to another and even within the same country from one health organization to another. The most commonly used growth reference chart was the NCHS/WHO child reference growth standards, used in 13 of the 16 responding countries (81.3\%)
(Table 2). The MOH in 3 countries reported using other growth charts: Saudi Arabia used their own locally developed charts, while Lebanon used the British charts developed in 1995 by the Child Growth Foundation in London and Qatar was using the CDC2000 growth charts. Libya and Egypt used their local growth charts in university hospitals but the Egyptian MOH used the NCHS/ WHO charts for nutrition surveillance.

Weight-for-age growth charts were used for growth monitoring by the $\mathrm{MOH}$ in all the responding countries. Nine of the 16 countries (56.3\%) used weight-for-age growth charts for males and females separately, while 7 countries (43.8\%) used combined growth charts for males and females (Egypt, Morocco, Pakistan, Sudan, Syrian Arab Republic, United Arab Emirates and Yemen) (Table 2). The height-for-age and head circumference-for-age for males and females separately were used in 9 countries (56.3\%). Weight-forheight standards for growth were used by only 3 countries (18.8\%) (Jordan,

\begin{tabular}{ll}
\hline $\begin{array}{l}\text { Table } 1 \text { Countries of the Eastern Mediterranean Region that participated in the } \\
\text { survey and officials who responded from these countries }\end{array}$ \\
\hline Country & Officials that responded \\
\hline Egypt & $\mathrm{MCH} / \mathrm{MOHP}$ and National Nutrition Institute \\
Syrian Arab Republic & $\mathrm{MOH}$ \\
Bahrain & $\mathrm{MOH}$ \\
Jordan & $\mathrm{MOH}$ and University of Jordan \\
Kuwait & $\mathrm{MOH}$ \\
Lebanon & $\mathrm{MOH}$ and 8 other health, teaching and private \\
Libyan Arab Jamahiriya & $\mathrm{Organizations}$ \\
Morocco & $\mathrm{MOH}$ \\
Pakistan & $\mathrm{MOH}$ \\
Palestine & $\mathrm{MOH}$ of West Bank, Ramallah \\
Qatar & $\mathrm{MOH}$ \\
Saudi Arabia & $\mathrm{MOH}$ \\
Sudan & $\mathrm{MOH}$ \\
Oman & $\mathrm{MOH}$ (Nutrition Department) and Institute of Nursing \\
Yemen & In depth study in 3 regions \\
United Arab Emirates & $\mathrm{UAE} / \mathrm{MOH}$, and Department of Health and Medical \\
& Services, Dubai \\
\hline
\end{tabular}

$\mathrm{MOH}=$ Ministry of Health; $\mathrm{MCH} / \mathrm{MOHP}=$ Maternal and Child Health Directorate/Ministry of Health and Population.
Kuwait and Qatar). Mid-arm circumference was used in 2 countries (12.5\%) (Pakistan and Libyan Arab Jamahiriya). Reference charts for body mass index (BMI) were used by 1 country (Lebanon), and also by some Libyan and Egyptian universities based on locally developed standards.

The classification system in use was reported to be based on the percentile system in 13 countries (81.3\%), except in Qatar, Oman and Pakistan, which reported the use of the $z$-score or standard deviation value system rather than percentiles. The Sudanese MOH mentioned that it used the percentage from the median in its child health services. The reasons for using the cut-off points was reported by all $\mathrm{MOH}$ officials to be based on recommendations based on the international agency and/or technical advisor (Table 3).

The common problems or constraints encountered in child growth monitoring programmes were categorized into informational, tangible and attitudinal. The informational constraints included lack of adequate training of personnel (reported by the $\mathrm{MOH}$ in 6 countries, $37.5 \%$ ), followed by poor understanding of the risk of overweight (5 countries, $31.3 \%$ ) and inaccurate plotting of growth data ( 5 countries, 31.3\%) (Figure 1). Also, difficulties with understanding and interpretation of growth reference curves were frequently reported (4 countries, $25.0 \%$ ). Tangible constraints included poor condition of weighing scales: lack of maintenance, standardization and timely replacements (4 countries, 25.0\%). Attitudinal constraints were less common, but still a problem and included poor understanding by health care workers of the risk of underweight and the importance of identifying and referring these children ( 3 countries 18.8\%)

The measurement of height and use of weight-for-height charts was agreed to be an important measurement needed to be added to growth assessment by 


\begin{tabular}{|c|c|c|c|c|c|c|c|c|}
\hline \multirow[t]{3}{*}{ Index } & \multicolumn{2}{|c|}{ Index monitored } & \multicolumn{4}{|c|}{ Growth reference chart used } & \multicolumn{2}{|c|}{ How chart used } \\
\hline & Yes & No & $\begin{array}{l}\text { NCHS/ } \\
\text { WHO }\end{array}$ & CDC2000 & British & Local & Combined & $\begin{array}{c}\text { Males/ } \\
\text { females } \\
\text { separately }\end{array}$ \\
\hline & No. & No. & No. & No. & No. & No. & No. & No. \\
\hline Weight-for-age & 16 & 0 & 13 & 1 & 2 & 1 & 7 & 9 \\
\hline Height-for-age & 11 & 5 & 8 & 2 & 2 & 1 & 2 & 9 \\
\hline Weight-for-height & 3 & 13 & 3 & 1 & 0 & 0 & 0 & 3 \\
\hline Head circumference & 11 & 5 & 8 & 1 & 2 & 1 & 2 & 9 \\
\hline Mid-arm circumference & 2 & 14 & 1 & 0 & 0 & 0 & 1 & 1 \\
\hline Body mass index & 1 & 15 & 0 & 0 & 1 & 0 & 0 & 1 \\
\hline
\end{tabular}

NCHS/WHO = National Center for Health Statistics/World Health Organization; CDC2000 = Centers for Disease Control 2000.

all except 1 of the respondents. Some countries were already doing this but not reporting it, as in the Gulf countries and in Egypt. Problems that might be faced if height measurement was introduced were: lack of trained personnel (reported by the $\mathrm{MOH}$ in 8 countries), lack of equipment (8 countries) and lack of time during the growth monitoring session (6 countries) (Table 3 ).

\section{Feedback}

Almost all respondents gave suggestions for improving the usefulness of child growth charts for monitoring. The following recommendations were mentioned.

Yemen officials suggested the use of coloured sections for the percentiles in the growth charts to make it easy for illiterate mother to monitor their child's growth and recognize the danger zones. They also suggested integrating the child growth chart with the immunization card of each child.

Lebanese officials suggested printing the charts for health staff including weight-for-age, height-for-age, and weight-for-height reference charts with built-in tables for numerical data and dates so that the health worker could record all growth data on 1 chart.

Yemeni and Libyan officials suggested spacing out columns for the first
3 months of life to facilitate monitoring over short periods of time.

Jordanian officials suggested the inclusion of the Ten Steps to Successful Breastfeeding as outlined by UNICEF/ WHO [14] within the child's card.

In line with the Child Rights Convention (article 34), Yemeni and Sudanese officials suggested lobbying for growth charts to be issued with the birth certificate as the right of every child to health and adequate nutrition.

Egyptian and Libyan officials suggested integrating information about developmental changes in children and feeding recommendations along the growth chart; also to alert mothers to the use of a family planning method.

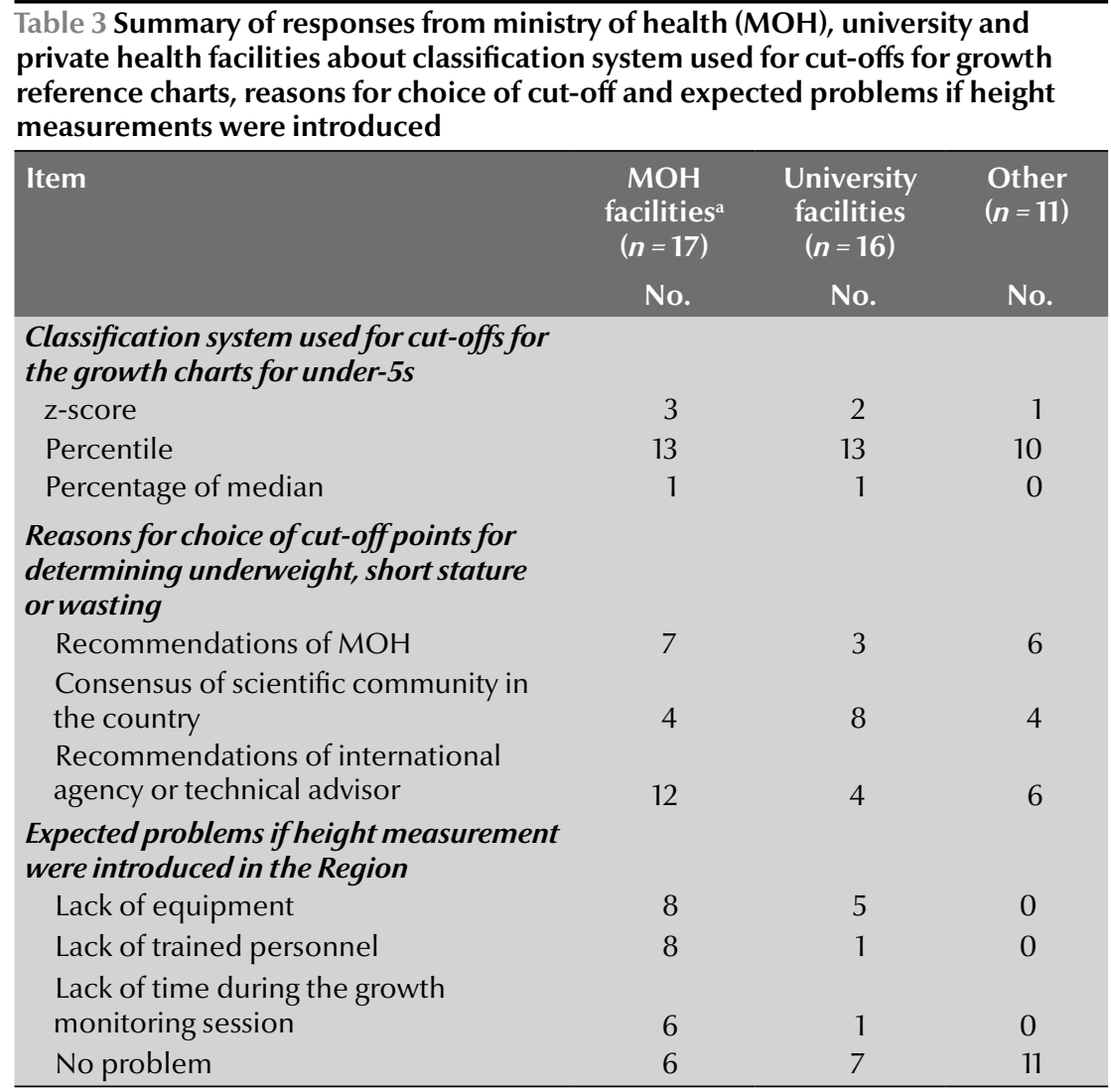

Data were missing in some categories and some respondents gavemore than one reason.

${ }^{a}$ One country (United Arab Emirates) reported data from 2 ministries of health (Abu Dhabi and Dubai). 


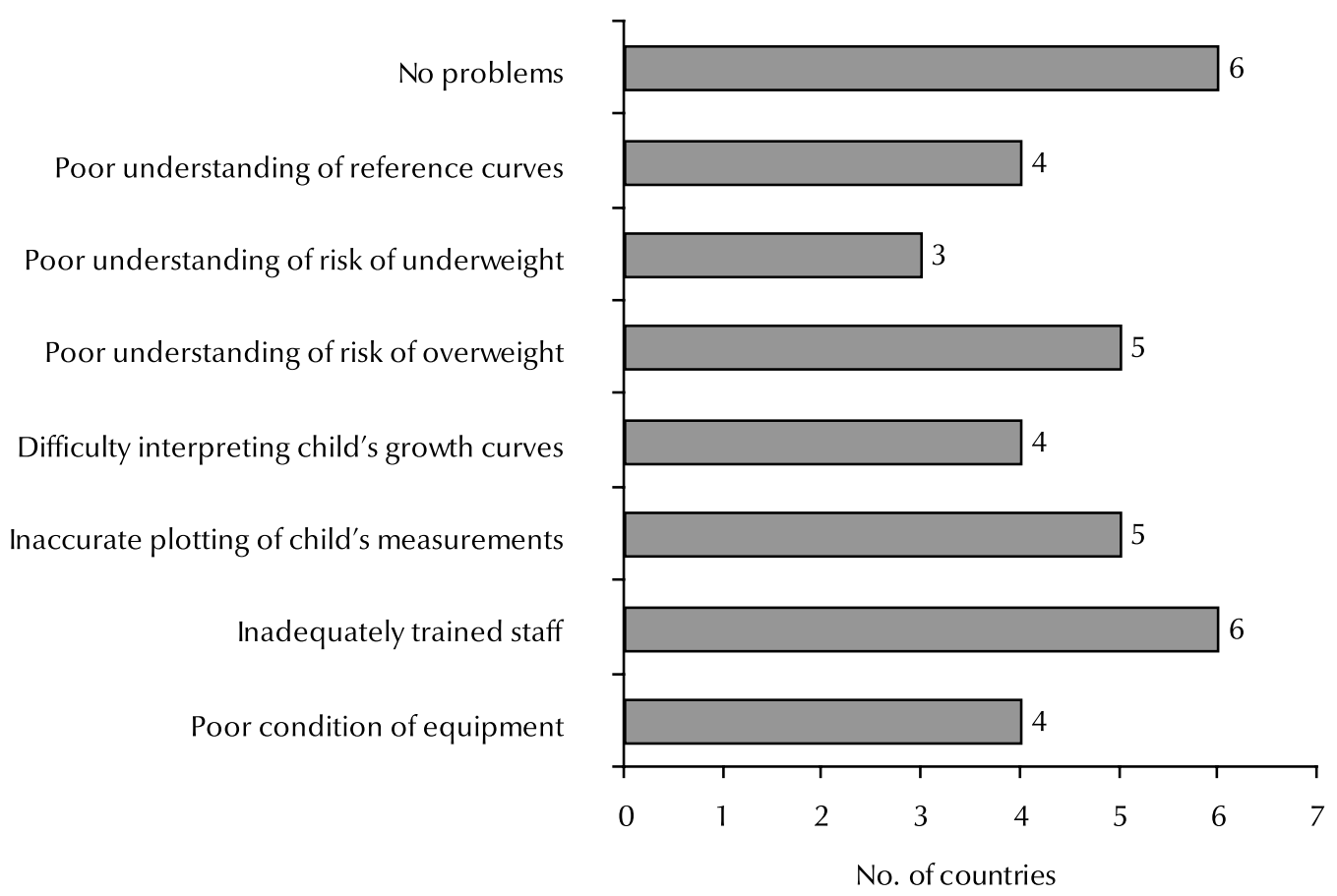

Figure 1 Number of countries who reported problems related to current use of growth reference charts in 16 countries of the Eastern Mediterranean Region

Finally they suggested that the growth chart could be integrated prenatally into the maternal and fetal assessment card to inform pregnant women about the benefits and implementation of growth monitoring.

\section{Discussion}

The survey clearly showed that the $\mathrm{MOH}$ in the majority of countries in the EMR used the NCHS/WHO growth chart as recommended by experts. The use of combined charts is more convenient for less affluent countries as it minimizes the cost of printing and distribution $[3,15]$.

A similar study was conducted by de Onis et al. on the practices of child growth monitoring in 202 countries [16]. The response rate ( $88 \%)$ was slightly higher than our response rate (76\%) probably due to the high percentage of countries in conflict and disaster situations in our Region. Their study showed similar findings. All countries in other regions used weight-for-age, but only half used it alone. Their study showed that the use of more than 1 type of growth standard was linked to affluence because more European than Asian countries used more than 1 type of growth chart. Such findings indicate that the universal problem for use of more than 1 type of growth chart is budgetary considerations and cost. Hence it is important to consider this when printing growth charts so that 1 unified chart includes all 4 essential measurements: weight-for-age, heightfor-age, head circumference-for-age and weight-for-height.

Many of the EMR countries in our study preferred to use percentile curves rather than $z$-scores. De Onis et al. reported this to be common in their studies in other regions of the world; only one-fifth of countries used $z$-scores [16]. This could arise as a problem in nutritional surveillance when comparing one country with another, and should be taken into consideration when unifying global child growth charts.
In April 2006 WHO released the WHO-CGS, the new standards for assessing the growth and development of children from birth to 5 years of age [17], which was developed from the WHO multicentre growth reference study conducted between 1997 and 2003 in Brazil, Ghana, India, Norway, Oman and the United States of America[14]. The WHO-CGS are based on the children of mothers of favourable socioeconomic status and who were exclusively, or predominantly, breastfed for at least 4 months and had complementary foods introduced from 6 months with continued breastfeeding for 2 years or more. Full term, lowbirth-weight infants were not excluded. Breastfed babies have higher growth rates in the first 3 months of life than children fed formula milk, as shown in various studies $[2,3,5,18-21]$. Hence findings from the study of the differences between the previous CDC2000 growth charts and the newly developed WHO-CGS are mainly reflected in lower rates of undernutrition and higher 
rates of overnutrition and obesity in the first 6 months [17].

The high infant mortality rate in EMR countries is closely linked with high rates of wasting. EMR countries with a high prevalence of wasting (over $10 \%)$ are those with a median infant mortality rate of 72 per 1000 compared with a median of 22.5 per a 1000 for countries with wasting prevalence below $10 \%$. Infant feeding practices and malnutrition are closely linked in EMR countries. The median rate of exclusive breastfeeding for 6 months is $27 \%$ and of continued breastfeeding at 20-23 months is $23 \%$. Timely complementary feeding between 6 and 9 months of age is lowest in Somalia (13\%) and highest in Oman (92\%), with a median of $51 \%$. The lowest rates of exclusive breastfeeding were shown to be associated in most countries with high prevalence of wasting (>10\%) [22-34].

With the use of the new WHOCGS for monitoring growth and nutritional status we expect to detect more cases of undernutrition in the first 6 months, reflecting the steep fall in exclusive breastfeeding practices. When corrected early, this can prevent the higher rates of undernutrition reported in our surveillance systems in the latter half of the first year.

Although the EMR has many problems related to nutritional disorders, the use of nutritional indices as a national scale for detecting undernutrition or overnutrition is not common in the Region. Countries that use weight-forheight as an indicator for wasting in their national system were Jordan, Kuwait and Qatar, only $18.8 \%$ of the surveyed countries. Thus the new WHO-CGS will be expected to reinforce the early detection of malnutrition by the use of weight-for-height. Although lack of training and necessary equipment were mentioned as the main obstacles to its adoption by countries, the WHO-CGS can be easily integrated through other child health programmes that support exclusive breastfeeding as the main standard for optimal infant growth, including the Baby Friendly Hospital Initiative, the Integrated Management of Childhood Illness and other maternal and child health and nutrition programmes [17-21,35].

The mid-arm circumference growth chart was used only in the Pakistani health care system. In other countries it is used by university hospitals for research purposes. BMI growth charts were rarely reported to be used by countries for the assessment of overweight or obesity at the primary health care level. The new WHO-CGS includes BMI-forage growth charts that are dramatically different from the previous CDC2000 charts. Estimates of overweight and obesity will increase substantially when the BMI-for-age standard is introduced in the EMR. Already childhood obesity is reported as a problem in countries such as Kuwait and Libyan Arab Jamahiriya [36-39]. We expect this problem will further magnify in these countries and appear in other countries where it was not previously recognized.

The problems facing growth monitoring programmes in the EMR were categorized into attitudinal, information and tangible. Attitudinal problems were related to poor understanding of the risk of overweight and underweight. The former is serious, as health staff and mothers do not perceive overweight in children as a problem; on the contrary they perceive it as an indication of good health. Hence intensive awareness campaigns need to be initiated in response to this. Poor feeding practices such as formula milk and feeding weaning foods in a bottle are one of the main causes for obesity at this age. Hence vigorous action should be taken to promote awareness of the hazards of formula feeding in bottles and especially after 6 months of age and during the second year, when family foods should be mandated. Available estimates for the period between the 1980s and 1990s show that the prevalence of overweight and obesity in children increased 2-5fold between the 1980s and 1990s in developed countries (e.g. from $11 \%$ to over 30\% in boys in Canada), and almost 4-fold in developing countries. Appraisal of 158 articles from 147 programmes showed that the preschool years may be a critical period for obesity prevention, as indicated by the association of adiposity rebound and obesity in later years [40].

The use of technology can influence changes at the practice level, such as incorporating the BMI-for-age index into office systems, and electronic medical records may be needed to support paediatric primary care providers in using BMI routinely. Educational interventions that address individual providers' concerns about screening recommendations and treatment effectiveness may be necessary $[41,42]$.

Other problems reported in our study and others [43] were informational owing to lack of knowledge and skills in the use and interpretation of growth charts. Researchers in Egypt reported a considerable improvement in the use of growth charts and reporting systems after training staff in primary health care on the skills of growth monitoring $[44,45]$. Incorporation of growth monitoring into training courses in child health and development, especially on the subject of breastfeeding and complementary feeding, has been shown to increase the effectiveness of these training programmes [46]. Recently WHO has developed training modules for health workers in child growth assessment that are tailored to the needs expressed by health workers during surveys to assess the use and implementation of child growth charts [47].

In conclusion, promotion of child growth monitoring should be able to reinforce the Global Strategy of Infant and Young Child Feeding and the Millennium Development Goals for preventing malnutrition and reducing infant mortality rates [38]. This can be 
achieved through promoting optimal infant feeding practices by the support of early exclusive breastfeeding from birth to 6 months of life and timely, adequate complementary feeding from 6 months onwards, with continued breastfeeding for 2 years or more through the Baby Friendly Hospital Initiative, the Integrated Management of Childhood Illness and maternal and child health programmes. However it will require intensive efforts by the countries of the EMR to adopt and institutionalize the newly developed global WHO-CGS.

\section{Acknowledgements}

We extend our gratitude to the efforts and facilitations offered by their
Excellencies the Ministers of Health, General Directorates of Maternal and Child Health, and the Nutrition Department in the MOH of all the 16 countries surveyed, particularly in Libyan Arab Jamahiriya, Yemen and Egypt. Our gratitude also goes to to the university staff visited in each of the shabiyat visited in Libyan Arab Jamahiriya and in Yemen.

\section{References}

1. Global strategy for infant and young child feeding. Geneva, World Health Organization, 2003.

2. Behague D. Growth monitoring and the promotion of breastfeeding. Social science \& medicine, 1993, 37(12):1565-78.

3. Dixon RA. Cost-effectiveness of growth monitoring and promotion. Lancet, 1993, 342:317.

4. De Onis M, Blossner M. WHO global database on child growth and malnutrition. Geneva, World Health Organization, 1997.

5. Garza C, de Onis M. WHO Multicentre Growth Reference Study Group. Rationale for developing a new international growth reference. Food and nutrition bulletin, 2004, 450:76-85.

6. Dewey KG et al. Growth of breast-fed and formula-fed infants from 0 to 18 months: the DARLING Study. Pediatrics, 1992, 89:1035-41.

7. Dewey KG. Growth patterns of breastfed and current status of growth charts for infants. Journal of human lactation, 1998, 14(2):89-92.

8. De Onis M, Onyango AW. The Centers for Disease Contro and Prevention 2000 growth charts and growth of breastfed infants. Acta paediatrica, 2003, 92:413-9.

9. Victora CG et al. The NCHS reference and the growth of breastand bottle-fed infants. Journal of nutrition, 1998, 128(7):1134-8.

10. De Onis M, Habicht J. Anthropometric reference data for international use: Recommendations from a WHO Expert Committee. American journal of clinical nutrition, 1996, 64(4):650-8.

11. WHO Multicentre Growth Reference Study Group. WHO Child Growth Standards based on length/height, weight and age. Acta paediatrica, supplement, 2006, 450:76-85.

12. Onyango AW et al. Field-testing the $\mathrm{WHO}$ child growth standards in four countries. Journal of nutrition, 2007, 137(1):149-52.

13. De Onis $\mathrm{M}$ et al. Comparison of the WHO child growth standards and the CDC 2000 growth charts. Journal of nutrition, 2007, 137(1):144-8.

14. Ten steps to successful breastfeeding. Information. United Nations Children's Fund [online article] (http://www.unicef.org/ newsline/tenstps.htm, accessed 18 August 2009).

15. Bågenholm G, Kristiansson B, Nasher AA. Growth and malnutrition among preschool children in Democratic Yemen. Bulletin of World Health Organization, 1988, 66(4):491-8.

16. De Onis M, Wijnhoven TMA, Onyango AW. Worldwide practices in child growth monitoring. Journal of pediatrics, 2004 144:461-5.

17. De Onis M et al. Comparison of the WHO Child Growth Standards and CDC 2000 Growth Charts. Journal of nutrition, 2007, 137:144-8.

18. WHO working group on the Growth Reference Protocol and WHO Task Force on Methods for the Natural Regulation of
Fertility 2000. Growth patterns of breastfed infants in seven countries. Acta paediatrica, 2000, 89:215-22.

19. Report of the Expert Consultation on the Optimal Duration of Exclusive Breastfeeding, Geneva, Switzerland, 28-30 March 2001. Geneva, World Health Organization, 2002.

20. Hijazi SS, Abulaban A, Waterlow JC. The duration for which exclusive breast-feeding is adequate. A study in Jordan. Acta paediatrica scandinavica, 1989, 78(1):23-8.

21. Kalies $\mathrm{H}$ et al. The effect of breastfeeding on weight gain in infants: results of a birth cohort study. European journal of medical research, 2005, 10(1):36-42.

22. Hosseini M, Carpenter RG, Mohammad K. Growth of children in Iran. Annals of human biology, 1998, 25(3):249-61.

23. Ayatollahi SMT, Ahmadi K. Infant growth charts for southern Iran. Annals of human biology, 2001, 28(3):337-45.

24. Djibouti family health survey. PAPFAM-final report. Rabat, Morocco, Ministry of Health and League of Arab States, 2004.

25. Al-Jaber KA, Farid SM. Qatar family health survey 1998. Principle report. Gulf family health survey. League of Arab States. Doha, Qatar Ministry of Health, 2000.

26. El-Zanaty F, Way A. Nutritional status of children: 2008 EDHS Data according to the NCHS/CDC/WHO international reference population. In: Egypt demographic and health survey 2008. Cairo, Egypt, Ministry of Health and Population, El-Zanaty and Associates, and Macro International, 2009.

27. Hafadh $\mathrm{N}$ et al. Bahrain family health survey 1995. Principle report. Gulffamily health survey. Manama, Bahrain, Ministry of Health and League of Arab States, 2000.

28. Hameida J, Billot L, Deschamps JP. Growth of preschool children in the Libyan Arab Jamahiriya: regional and sociodemographic differences. Eastern Mediterranean health journal, 2002, 8(4/5):458-69.

29. Kamal AA et al. Growth pattern of Qatari preschool children Croatian medical journal, 2004, 45(4):461-5.

30. Sudan family health survey 1992/93, Principle report. Khartoum, Sudan, Ministry of Health and League of Arab States, 1995.

31. Suliman A, Al Riyami A, Farid S. Oman family health survey 1995. Principle report. Gulffamily health survey. Muscat, Oman, Ministry of Health and League of Arab States, 2000.

32. Syrian family health survey 2000. Principle report. Damascus, Syrian Arab Republic, Supreme Council of Ministers and League of Arab States 2002.

33. Tajouri RF. Cross-sectional study of growth in urban pre-school children in Libya [PhD thesis]. Zurich, University Zurich, University Children's Hospital, 1979. 
34. Tawfeek H, Al Mashikhi SA, Salom A. The Iraqi national nutrition survey: correlation between various anthropometric measurements as indicators of severity of malnutrition. Food and nutrition bulletin, 1998, 19(4):318-20.

35. Haschke F, van't Hof MA. Euro-growth references for breastfed boys and girls: influence of breast-feeding and solids on growth until 36 months of age. Euro-Growth Study Group. Journal of pediatric gastroenterology and nutrition, 2000, 31(Suppl. 1):S60-71.

36. Al-Isa AN, Moussa MA. Obesity among Kuwait preschool children aged 0-5 years: prevalence and comparison with NCHS/ CDC reference. Nutrition and health, 1998, 12:235-48.

37. Hakeem R. Socio-economic differences in height and body mass index of children and adults living in urban areas of Karachi, Pakistan. European journal of clinical nutrition, 2001, 55:400-6.

38. Millennium development goals: background. United Nations [website] (http://www.un.org/millenniumgoals/bkgd.shtml, accessed 18 August 2009).

39. Hameida J, Billot L. Nutritional status of Libyan children in 2000 compared with 1979. Eastern Mediterranean health journal, 2002, 8(2-3):261-71.

40. Flynn MA et al. Reducing obesity and related chronic disease risk in children and youth: a synthesis of evidence with "best practice" recommendations. Obesity reviews, 2006, 7(Suppl. 1):7-66.
41. Spooner SA, Council on Clinical Information Technology. Special requirements of electronic health record systems in pediatrics. Pediatrics, 2007, 119(3):631-7.

42. Flower KB et al. Using body mass index to identify overweight children: barriers and facilitators in primary care. Ambulatory pediatrics, 2007, 7(1):38-44.

43. Dixon RA, Sutton P. Child growth monitoring: errors of measurement with the TALC direct recording scale. Journal of tropical pediatrics, 1994, 40:376-8.

44. Salem KA et al. The effects of a training program on knowledge, attitude and practice of the staff of primary health care centers towards growth monitoring: an intervention study. Journal of the Egyptian Public Health Association, 1999, 74(5-6):627-49.

45. Youssef $\mathrm{N}$ et al. Utilization of growth monitoring to evaluate the effects of a teaching program given to mothers of infants about nutrition. New Egyptian journal of medicine, 1993, 8(1):313-9.

46. Haggerty PA, Rutstein SO. Breastfeeding and complementary infant feeding and the postpartum effect of breastfeeding. Calverton, Maryland, Macro International, 1999 (Demographic and Health Surveys Comparative Studies No. 30).

47. Training course on child growth assessment. Version I. November, 2006, Geneva, World Health Organization, 2006

\section{WHO Global Database on Child Growth and Malnutrition}

The WHO Global Database on Child Growth and Malnutrition was initiated in 1986 to collect, standardize and disseminate child anthropometric data in a uniform format.

The database includes population-based surveys that fulfil common inclusion criteria related to sampling frame and procedure, sample size and standard measurement techniques. Data are checked for validity and consistency and raw data sets are analysed following a standard procedure to obtain comparable results. The prevalence of wasting, stunting, and over- and underweight in preschool children are presented using z-scores based on the WHO Child Growth Standards and the National Center for Health Statistics (NCHS)/WHO international reference population.

Detailed country data and references can be accessed at: www.who.int/nutgrowthdb. This website also provides further information on the database, direct links to summary papers, link to download the WHO Standards and software/ macros to analyse nutritional survey data. 